\title{
Active Transport of Proline by Coxiella burnetii
}

\author{
By LAURA HENDRIX* AND LOUIS P. MALLAVIA \\ Department of Bacteriology and Public Health, Washington State University, Pullman, \\ WA 99164-4340, USA
}

(Received 7 March 1984; revised 26 June 1984)

The obligate intracellular rickettsia, Coxiella burnetii, was shown to possess an energy dependent proline transport system which displayed a high degree of specificity and was highly dependent on pH. Transport was maximal at $\mathrm{pH} 3.0$ to 4.5 , a $\mathrm{pH}$ range approximating that of the host cell phagolysosome where the agent replicates. Transport was inhibited by the uncouplers carbonyl cyanide $m$-chlorophenylhydrazone and dinitrophenol, but not by sodium arsenite. In the presence of glutamate, a preferred energy source, proline uptake was enhanced more than twofold. This enhancement of proline uptake was greatly decreased in the presence of sodium arsenite. The addition of glutamate decreased the apparent $K_{\mathrm{m}}$ for proline transport from $45 \mu \mathrm{M}$ to $15 \mu \mathrm{M}$, with the $V_{\max }$ increasing from $3.6 \mathrm{pmol} \mathrm{s}^{-1}$ ( $\mathrm{mg} \mathrm{dry} \mathrm{wt}^{-1}$ to $4.8 \mathrm{pmol} \mathrm{s}^{-1}$ (mg dry wt) $)^{-1}$. Two proline analogues, furoic acid and azetidine-2-carboxylic acid, were effective inhibitors of proline transport. D-Proline, 4-hydroxyproline, glycine and proline amide inhibited transport minimally, while no inhibition was seen with succinate, pyruvate or glutamate.

\section{INTRODUCTION}

Coxiella burnetii, an obligate intracellular rickettsia with a high degree of resistance to adverse environmental conditions, survives and replicates in the phagolysosome of phagocytic cells (Burton et al., 1978). Even though extracts of $C$. burnetii appear to possess a variety of enzymes necessary for growth, minimal metabolic capabilities are exhibited by intact cells outside the eukaryotic host at neutral pH (Baca \& Paretsky, 1983; Weiss, 1982). A recent report on glutamate and glucose transport by $C$. burnetii at $\mathrm{pH}$ ranges approximating those of the phagolysosome (Hackstadt \& Williams, 1981 a) suggests that the organism may be unable to grow at neutral $\mathrm{pH}$ because it cannot generate a sufficient electrochemical gradient of $\mathrm{H}^{+}\left(\Delta \bar{\mu}_{\mathrm{H}^{+}}\right)$to drive transport processes.

We have begun a study of $\mathrm{pH}$ dependent transport of amino acids to determine if this is a general phenomenon. Of the amino acids thus far examined (leucine, methionine, lysine, proline and glutamate) significant levels of uptake were detectable only for proline and glutamate. While these findings seemed surprising, lysosomal extracts inhibited uptake of lysine, valine, leucine, methionine and phenylalanine, but not of glutamate or proline in Candida albicans (Peterson \& Calderone, 1978). Thus, the transport and utilization of glutamate and proline could be important to survival in the lysosomal environment. Coxiella burnetii appears to require a low pH for transport (Hackstadt \& Williams, $1981 a, 1983$ ) and possibly for this reason will only replicate within the phagolysosome. The study of proline transport and utilization may provide clues to the mechanisms by which $C$. burnetii has adapted to this hostile environment. In this report we present the characterization of the $\mathrm{pH}$ dependent transport of proline by $C$. burnetii in terms of kinetic properties, energy dependence and specificity. A preliminary account of this work has already appeared (Hendrix \& Mallavia, 1983).

Abbreviations: CCCP, carbonyl cyanide m-chlorophenylhydrazone; pCMBS, p-chloromercuriphenylsulphonic acid; DNP, 2,4-dinitrophenol; NEM, N-ethylmaleimide. 


\section{METHODS}

Organism. The Nine Mile strain of Coxiella burnetii, phase I, clone 7 (Rocky Mountain Laboratories, Hamilton, Mont., USA) was propagated in 6-d-old fertile hen's eggs (straight run, antibiotic-free; H \& N Hatchery, Redmond, Wash., USA). Infected yolk sacs of viable embryos were harvested at $8 \mathrm{~d}$ and frozen for convenience at $-20^{\circ} \mathrm{C}$ until use.

Purification. Coxiella burmetii was purified from frozen infected yolk sacs by a modification of the methods of Ribi \& Hoyer (1960) and Williams et al. (1981). Purification was begun with homogenization of 20 to $30 \mathrm{~g}$ of yolk sacs on ice in a Sorvall Omni-mixer for $2 \mathrm{~min}$ in $100 \mathrm{ml}$ of sucrose/phosphate buffer, pH 7.4, containing $72.6 \mathrm{~mm}-$ $\mathrm{NaCl}, 12.8 \mathrm{mM}-\mathrm{KH}_{2} \mathrm{PO}_{4}, 53.9 \mathrm{~mm}-\mathrm{Na}_{2} \mathrm{HPO}$ and $250 \mathrm{mM}$-sucrose. This was followed by centrifugation for $45 \mathrm{~min}$ at $10000 \mathrm{~g}$. After removal of the supernatant and lipid layer, the pellet was suspended in $20 \mathrm{ml}$ sucrose/ phosphate buffer, rehomogenized and layered over $180 \mathrm{ml}$ ice-cold $30 \%(w / w)$ sucrose in phosphate-buffered saline (sucrose/phosphate buffer without sucrose). Centrifugation was carried out for $60 \mathrm{~min}$ at $1000 \mathrm{~g}_{\mathrm{g}}$ and allowed to come to a stop without the brake. All but the well-pelleted material was removed. The pellet was then resuspended in $20 \mathrm{ml}$ sucrose/phosphate buffer and centrifuged at $200 \mathrm{~g}$ for $10 \mathrm{~min}$. The supernatant was removed by aspiration, diluted in sucrose/phosphate buffer and fittered over a single AP 20 filter (Millipore). The filtrate was centrifuged at $1000 \mathrm{~g}_{\mathrm{g}}$ for $30 \mathrm{~min}$. The pellet was then resuspended in $5 \mathrm{ml}$ sucrose/phosphate buffer and layered over a 30 to $60 \%$ (w/w) sucrose gradient. Gradients were centrifuged (SW 27 rotor) at $85000 \mathrm{~g}$ for $2 \mathrm{~h}$ in a Beckman L5-50 ultracentrifuge. Rickettsial bands were removed, diluted in sucrose/phosphate buffer and centrifuged to pellet the organisms at $10000_{\&}$ for $45 \mathrm{~min}$. The pellet was resuspended in sucrose/phosphate buffer and concentration in terms of dry weight was determined by reading the optical density in a Klett-Summerson colorimeter at $420 \mathrm{~nm}$ using a standard curve (Williams et al., 1981). Rickettsiae in yolk sac smears and purified preparations were identified by the method of Gimenez (1964).

Transport studies. Initial rates of proline transport were determined as described by Hackstadt \& Williams $(1981$ a). Levels of glutamate transport in C. burnetii purified from frozen yolk sacs were similar to those reported by Hackstadt \& Williams ( 1981 a) for organisms purified from freshly harvested yolk sacs. Freshly purified $C$. burnetii were suspended at a concentration of $5 \mathrm{mg}$ dry wt $\mathrm{ml}^{-1}$ in P-25 buffer (25 mM-potassium phosphate, $15 \mathrm{~mm}$ $\mathrm{NaCl}, 152.5 \mathrm{mM}-\mathrm{KCl}$ and $100 \mathrm{~mm}$-leucine or glycine) at the desired $\mathrm{pH}$. Leucine was substituted for glycine in those experiments where the effect of glycine on proline transport was examined. The transport medium consisted of P-25 buffer with $350 \mu \mathrm{Ci}(12.95 \mathrm{MBq}) \mathrm{L}-\left\{2,3,4,5 .{ }^{3} \mathrm{H}\right)$ proline $\mu \mathrm{mol}^{-1}\left(7 \mu \mathrm{Ci} \mathrm{ml}^{-1}\right)$. Additional components, such as unlabelled substrates, were prepared in $\mathrm{P}-25$ buffer and, when necessary, adjusted to the desired pH with $\mathrm{NaOH}$ or $\mathrm{HCl}$. Carbonyl cyanide m-chlorophenylhydrazone (CCCP), 2,4-dinitrophenol (DNP) and $N$-ethylmaleimide (NEM), were prepared in $95 \%(v / v)$ ethanol and added to the transport medium at a dilution of $1: 100$. This concentration of ethanol did not affect levels of transport in control reactions without inhibitors. Organisms were equilibrated for $4 \mathrm{~min}$ at $37^{\circ} \mathrm{C}$ in the transport medium and transport was initiated by the addition of prewarmed substrate. Metabolic inhibitors were allowed to preincubate with cells for $15 \mathrm{~min}$ before the addition of substrate. In studies of structurally related inhibitors, unlabelled substrates and $\left[{ }^{3} \mathrm{H}\right]$ proline were equilibrated for $4 \mathrm{~min}$ in transport medium and the reaction was begun by the addition of the organism. Samples of $100 \mu \mathrm{l}$ were removed and filtered immediately through pre-wetted filters of $0.2 \mu \mathrm{m}$-pore diameter (GSWP; Millipore) followed by a $15 \mathrm{ml}$ wash at room temperature with P-25 buffer without leucine or glycine, $\mathrm{pH}$ 6.8. The filters were removed from the filtration apparatus, placed in $7.5 \mathrm{ml}$ Aquasol Il (New England Nuclear) and their radioactivity was measured by liquid scintillation. Initial rates of transport were calculated from the linear portion of the uptake curve and are expressed as pmol proline $\mathrm{s}^{-1}\left(\mathrm{mg}_{\mathrm{g}} \mathrm{dry} \mathrm{wt}^{-1}\right)^{-1}$. All results shown are the average of at least three experiments done in duplicate. Variation was generally less than $10 \%$.

To correct for possible binding of isotope to filters, control reactions without cells were sampled and filtered as above. Radioactivity retained on the filters was generally about 100 c.p.m. and was subtracted from experimenta] values before calculations were carried out. Similar levels of binding occurred in control reactions with cells incubated on ice.

Analysis of intracellular radioactivity. Cells which had been incubated in $20 \mu \mathrm{M}-\mathrm{L}-\mathrm{U}-14 \mathrm{C})$ proline $(100 \mu \mathrm{Ci} \mu-$ $\mathrm{mol}^{-1}, 2 \mu \mathrm{Ci} \mathrm{ml} \mathrm{m}^{-1}$ ) for $90 \mathrm{~s}$ at $37^{\circ} \mathrm{C}$ with or without the addition of glutamate were pelleted rapidly in a microfuge and washed once in $0.14 \mathrm{~m}$-Tris buffer, $\mathrm{pH} 7.0$. The pellets were resuspended in $0.5 \mathrm{M}$-perchloric acid and incubated on ice for $30 \mathrm{~min}$. The cells were pelleted and the supernatant was neutralized with $\mathrm{KOH}$, incubated at $4^{\circ} \mathrm{C}$ overnight and centrifuged to remove salts. The supernatant was concentrated by lyophilization, resuspended in a small volume of distilled water and chromatographed against standards on silica gel instant thin layer plates (Gelman Instrument Co., Ann Arbor, Mich., USA) in phenol/ $\mathrm{H}_{2} \mathrm{O}(75: 25$, w/w) containing KCN (0.2 mg ml-1). Radioactivity was detected by autoradiography after spraying with En ${ }^{3}$ Hance spray (New England Nuclear).

Production of ${ }^{14} \mathrm{CO}_{2}$ from proline and incorporation of [1 ${ }^{4} \mathrm{C}$ ) duct were determined as described previously (Hackstadt \& Williams, 1981a).

Chemicals and radiochemicals. $L-\left\{2,3,4,5-{ }^{3} \mathrm{H}\right]$ Proline and $L-\left\{G^{-3} \mathrm{H}\right.$ glutamate were obtained from ICN Pharmaceuticals, Irvine, Calif., USA. L $\left\{\right.$ U- $\left.{ }^{14} \mathrm{C}\right\}$ Proline was obtained from New England Nuclear. L-Proline 
amide and 2-furoic acid were received from James C. Vary. University of Illinois Medical Center, Chicago, Ill., USA. All other reagents were from Sigma.

\section{RESULTS}

\section{pH dependence and kinetics}

Uptake of proline by $C$. burnetii was highly dependent on pH (Fig. 1). Rates of proline transport were maximal over a pH range of 3.0 to 4.5 at a proline concentration of $20 \mu \mathrm{M}$. Transport of glutamate and glucose by $C$. burnetii also occurs maximally at this pH range (Hackstadt \& Williams, $1981 a$ ). The $\mathrm{pH}$ of the host phagolysosome where $C$. burnetii replicates has been reported to be 4.7 to 4.8 (Ohkuma \& Poole, 1978). All further transport experiments were done at pH 4.0.

Transport of proline was linear for at least $90 \mathrm{~s}$. Initial rates of transport were calculated by least squares analysis over the linear portion of the uptake curve determined by plotting pmol of intracellular proline at 30,60 and $90 \mathrm{~s}$. The slope of the line was taken as the initial rate. At pH 4.0 and proline concentrations between 5 and $80 \mu \mathrm{M}$, the $K_{\mathrm{m}}$ for transport was determined from a plot of $v$ versus $v /[\mathrm{S}]$ (Dowd \& Riggs, 1965) to be $45 \mu \mathrm{M}$ and the $V_{\max }$ was $3.6 \mathrm{pmol} \mathrm{s}-1$ (mg dry wt) $)^{-1}$ (Fig. 2).

Although proline transport between 5 and $80 \mu \mathrm{M}$ showed saturation kinetics, with some purified preparations uptake rates began to increase again at $100 \mu \mathrm{M}$-proline and continued increasing up to $500 \mu \mathrm{M}$. Uptake also occurred at $\mathrm{pH} 7$ at these proline concentrations. In these instances the lack of saturation could be due to passive or facilitated diffusion or the activity of a second proline transport system of lower affinity.

C. burnetii appears to use glutamate as a preferred energy source (Hackstadt \& Williams, $1981 \mathrm{~b}$ ). When the organism was incubated in $5 \mathrm{~mm}$-glutamate for $15 \mathrm{~min}$ before the addition of labelled proline, proline uptake was greatly enhanced (Fig. 3). Intracellular substrate concentrations were determined assuming a cytoplasmic volume of $1.5 \mu \mathrm{l}$ (mg dry wt) ${ }^{-1}$ (Hackstadt, 1983). Ninety seconds after the addition of $\left[{ }^{3} \mathrm{H}\right]$ proline, a threefold concentration of label was achieved intracellularly. Preincubation of cells in the presence of $5 \mathrm{~mm}$-glutamate increased this

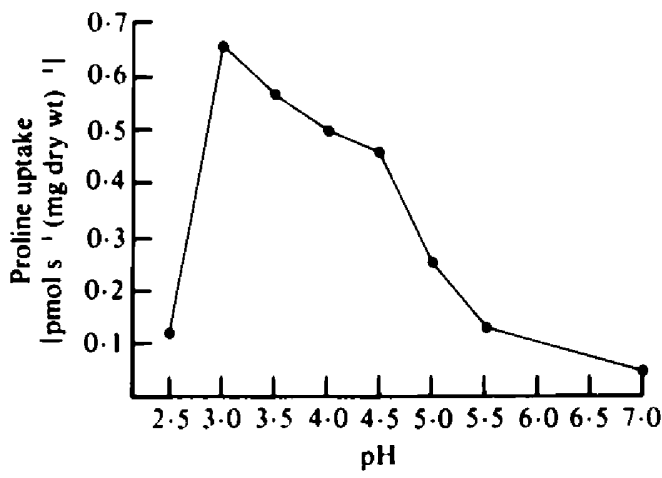

Fig. 1

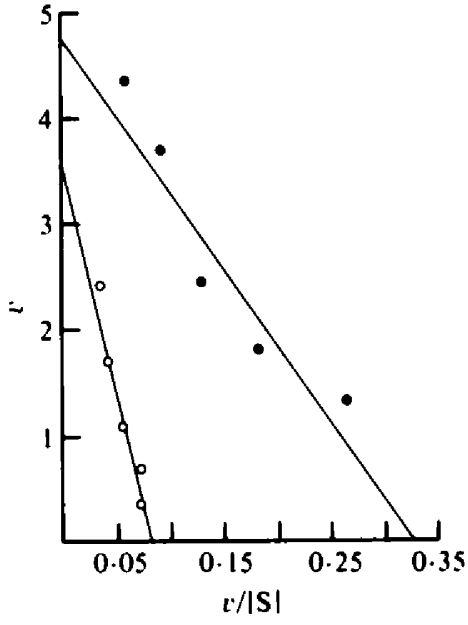

Fig. 2

Fig. 1. Uptake of proline as a function of pH. Purified organisms were resuspended in P-25 buffer of varied $\mathrm{pH}$ and rates of proline uptake $(20 \mu \mathrm{M})$ were determined. The final $\mathrm{pH}$ was determined from duplicate reaction mixtures and showed no change after 6 min incubation.

Fig. 2. Kinetics of proline transport in the presence and absence of $5 \mathrm{mM}$-glutamate. The concentration of proline, [S], was varied from 5 to $80 \mu \mathrm{M}$. $v$ is expressed as pmol $\mathrm{s}^{-1}$ ( $\mathrm{mg}$ dry wt) $)^{-1}$. O. No additions:

. plus 5 mM-glutamate. 
Table 1. Effect of metabolic inhibitors on proline transport by C. burnetii

$\begin{array}{lcc}\text { Inhibitor* } & \begin{array}{c}\text { Concn } \\ (\mathrm{mM})\end{array} & \begin{array}{c}\text { Percentage of } \\ \text { initial rates } \\ \text { of control }\end{array} \\ \mathrm{CCCP} & 0.05 & 5 \\ \mathrm{DNP} & 0.5 & 32 \\ \mathrm{NaF} & 1 & 59 \\ & 10 & 30 \\ \mathrm{NaAs} \mathrm{O}_{2} & 0.5 & 85 \\ & 0.5 \ddagger & 13 \ddagger \\ { }^{\circ} \mathrm{C} & & 4\end{array}$

\footnotetext{
- Inhibitort were added to cells in buffer at $37^{\circ} \mathrm{C}, 15 \mathrm{~min}$ before addition of labelled proline.

$\uparrow$ Data are expreseed as a percentage of the initial rates of the control [0.36-1.18 $\mathrm{pmol} \mathrm{s}^{-1}$ (mg dry wt) $\left.{ }^{-1}\right]$ oberved with $\left.20 \mu \mathrm{M}-{ }^{3} \mathrm{H}\right]$ proline $\left(350 \mu \mathrm{Ci} \mu \mathrm{mol}^{-1}\right)$ at $\mathrm{pH} 4.0$ in the absence of inhibitors.

\$ Data are expressed as a percentage of the initial rates of the control [5.67 $\mathrm{pmol} \mathrm{s}^{-1}$ ( $\mathrm{mg}_{\mathrm{g}} \mathrm{dry}$ wt) ${ }^{-1}$ ] observed with $20 \mu \mathrm{M}-\mathrm{f}^{3} \mathrm{H}$ )proline after incubation for $15 \mathrm{~min}$ in $5 \mathrm{mu}$-glutamate. Glutamate uptake was not affected by $\mathrm{NaA}_{8} \mathrm{O}_{2}$.
}

value to sevenfold. Because the enhancement of proline transport by glutamate appeared to require 15 min preincubation, the possibility that protein synthesis was required was examined. However, the addition of chloramphenicol $\left(100 \mu \mathrm{g} \mathrm{ml}^{-1}\right)$ had no effect on proline or glutamate transport. The kinetics of proline uptake were also examined after incubation in $5 \mathrm{mM}$ glutamate and initial rates were calculated as before. The $K_{\mathrm{m}}$ for proline transport after incubation in glutamate was $15 \mu \mathrm{M}$ calculated from a plot of $v$ versus $v /[S]$ and the $V_{\max }$ was $4.8 \mathrm{pmol} \mathrm{s}^{-1}$ (mg dry wt) $)^{-1}$ (Fig. 2). True saturation also did not always occur in the presence of glutamate.

\section{Fate of intracellular radiolabel}

Incorporation of $\left[{ }^{14} \mathrm{C}\right]$ proline into macromolecules was not detectable until $\mathrm{l} \mathrm{h}$ after the addition of radiolabel. ${ }^{14} \mathrm{CO}_{2}$ evolution equivalent to $10 \%$ of the intracellular radiolabel was seen by $5 \mathrm{~min}$. However, no ${ }^{14} \mathrm{CO}_{2}$ was detectable by $90 \mathrm{~s}$, the time course over which initial rates of transport were calculated. Since proline must be metabolized to another compound before decarboxylation, it was necessary to show by thin layer chromatography and autoradiography that no conversion of the substrate had occurred by $90 \mathrm{~s}$. Indeed, the only radioactivity visible by autoradiography co-migrated with the unlabelled proline standard.

\section{Energy dependence}

To determine the energy requirements for proline transport, the effects of several metabolic inhibitors were examined (Table 1). As has been shown for glutamate transport (Hackstadt \& Williams, 1983), only those compounds able to dissipate the $\Delta \bar{\mu}_{H^{+}}$across the bacterial membrane were effective inhibitors of proline transport, e.g. the uncouplers of oxidative phosphorylation $\mathrm{CCCP}$ and DNP. The enolase inhibitor $\mathrm{NaF}$ was also an effective inhibitor of proline transport in $C$. burnetii. It has been reported that at an acidic $\mathrm{pH}, \mathrm{NaF}$ is able to act as a transmembrane proton conductor (Eisenberg \& Marquis, 1981 ; Hackstadt, 1983). Sodium arsenite, an inhibitor of dihydrolipoyl dehydrogenase, did not greatly inhibit proline transport, but it greatly decreased the enhanced uptake of proline seen with added glutamate (Fig. 3). The reduction of proline transport under these conditions was shown not to be due to an inhibition of glutamate transport by sodium arsenite.

The greatest inhibition of proline transport occurred at $0{ }^{\circ} \mathrm{C}$ in the absence of any metabolic poisons. Rates of transport at $0{ }^{\circ} \mathrm{C}$ were $<5 \%$ of those seen at $37^{\circ} \mathrm{C}$.

\section{Specificity}

Various structurally related compounds were examined for their ability to inhibit proline transport (Table 2). At a 20-fold greater concentration than the labelled substrate, the two proline analogues azetidine-2-carboxylic acid and 2-furoic acid effectively inhibited L-proline 


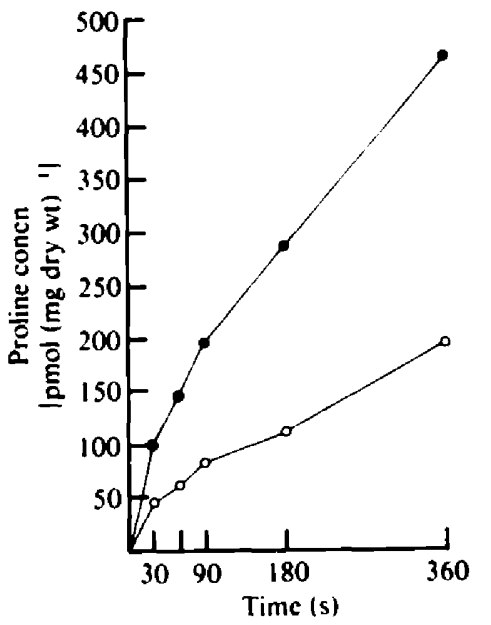

Fig. 3. Proline uptake in the presence and absence of $5 \mathrm{~mm}$-glutamate. The proline concentration was $20 \mu \mathrm{M}$. $O$. No additions; $O$. plus 5 mu-glutamate.

Table 2. Specificity of proline uptake in C. burnetii

$\begin{array}{lc}\text { Inhibitor* } & \begin{array}{c}\text { Percentage of } \\ \text { initial rates } \\ \text { of control† }\end{array} \\ \text { L-Proline } & 15 \\ \text { 2:Furoic acid } & 49 \ddagger \\ \text { L-Azetidine-2-carboxylic acid } & 51 \\ \text { D-Proline } & 82 \\ \text { Glycine } & 87 \\ \text { L-Proline amide } & 89 \\ \text { 4-Hydroxy-L-proline } & 92\end{array}$

\footnotetext{
- Concentration of unlabelled inhibitors was $400 \mu \mathrm{M}$. Inhibitors were added simultaneously with labelled proline.

Data are expreseed as a percentage of the initial rates of the control $\left[0.39 \mathrm{pmol} \mathrm{s}^{-1}\right.$ ( $\left.\mathrm{mg} \mathrm{dry} \mathrm{wt}^{-1}\right]$ observed with $20 \mu \mathrm{M}-{ }^{3} \mathrm{H}$ proline $\left(350 \mu \mathrm{Ci} \mathrm{mol}^{-1}\right)$ at $\mathrm{pH} 4.0$ in the absence of inhibitors. The following compounds did not effectively inhibit proline transport: L-glutamate, pyruvate and succinate; the percentage of the initial rates of the control were 96, 102 and 110 , respectively.

$\$ K_{i}$ determined from a Dixon plot was found to be $500 \mu \mathrm{m}$.
}

uptake. Minimal inhibition of proline transport was seen with D-proline, glycine, proline amide and 4-hydroxy-L-proline. The preferred substrates glutamate, succinate and pyruvate (Hackstadt \& Williams, $1981 b$ ) did not inhibit uptake. These results indicate that considerable structural similarity to proline is required for the molecule to be recognized by the transport system. Substitutions of the carboxyl group of proline (proline amide), additional hydroxyl groups (4-hydroxy-L-proline) or chiral rearrangements (D-proline) resulted in a decreased ability to inhibit L-proline uptake. Replacement of the secondary amine group of proline by oxygen (2-furoic acid) or a decrease in ring size (azetidine-2-carboxylic acid) were less detrimental to recognition of the molecule.

\section{Effects of thiol reagents}

The membrane permeable thiol reagent NEM significantly inhibited proline uptake (Table 3) in the presence or absence of $5 \mathrm{mM}$-glutamate. The membrane impermeable thiol reagent $p$ chloromercuriphenylsulphonic acid (pCMBS), was as effective as NEM at reducing proline uptake, indicating that a thiol group on a membrane carrier protein may be involved in transport. 
Table 3. Effect of thiol reagents on proline uptake by $C$. burnetii

$\begin{array}{lccc}\text { Inhibitor* } & \begin{array}{c}\text { Concn } \\ \text { (mM) }\end{array} & \text { S mM-Glutamate } & \begin{array}{c}\text { Percentage of } \\ \text { initial rates } \\ \text { of controlt }\end{array} \\ \text { pCMBS } & 5 & - & 3 \\ \text { pCMBS } & 5 & + & 0 \neq \\ \text { NEM } & 5 & - & 3 \\ & 1 & - & 21 \\ & 5 & + & 1 \ddagger\end{array}$

\footnotetext{
- Inhibitors were added to cells in buffer at $37^{\circ} \mathrm{C}, 15 \mathrm{~min}$ before addition of labelled proline.

$\dagger$ Data are expressed as a percentage of the initial rates of the control $\left[0.56-0.63 \mathrm{pmol} \mathrm{s}^{-1}\left(\mathrm{mg}_{\mathrm{g}} \mathrm{dry}\right.\right.$ wit) $\left.{ }^{-1}\right]$ observed with $\left.20 \mu \mathrm{M}-{ }^{3} \mathrm{H}\right]$ proline $\left(350 \mu \mathrm{Ci} \mu \mathrm{mol}^{-1}\right)$ at $\mathrm{pH} 4.0$ in the absence of inhibitors.

\$ Data are expressed as a percentage of the initial rates of the control [ $\left.2.80 \mathrm{pmol} \mathrm{s}^{-1}\left(\mathrm{mg}_{\mathrm{g}} \mathrm{dry} \text { wt) }\right)^{-1}\right]$ observed with $20 \mu \mathrm{M}-{ }^{3} \mathrm{H}$ /proline after incubation for $15 \mathrm{~min}$ in $5 \mathrm{mM}$-glutamate.
}

\section{DISCUSSION}

We have shown the presence of an energy dependent proline transport system in $C$. burnetii which displayed a high degree of specificity and was highly dependent on $\mathrm{pH}$. The $K_{\mathrm{m}}$ and $V_{\max }$ for proline transport were very similar to those observed for glutamate transport in $C$. burnetii at pH 4.0 (Hackstadt \& Williams, 1983). When organisms were preincubated in glutamate the apparent $K_{m}$ of proline uptake decreased by two-thirds, with the $V_{\text {max }}$ increasing to a lesser extent. Inhibitor studies implied that glutamate must be metabolized via the citric acid cycle to enhance proline uptake. Cells incubated without glutamate may convert some of the transported proline to glutamate to supply this energy-related function.

The possibility of a second proline transport system in $C$. burnetii recalls the multiple proline transport systems described in Salmonella typhimurium, Pseudomonas aeruginosa and Escherichia coli (Anderson et al., 1980; Kay \& Gronlund, 1969; Wood \& Zadworny, 1979). However, the inability to select for rickettsial mutants lacking one of the systems precludes detailed study at present. The pleomorphic nature of C. burnetii (McCaul \& Williams, 1981) may itself result in variability in transport activity.

Proline transport has been shown in $E$. coli to be driven by a $\Delta \bar{\mu}_{\mathrm{H}^{+}}$generated either by electron transport or ATP hydrolysis (Berger, 1973). The pH dependence of proline transport and its sensitivity to inhibition by the proton conductors CCCP, DNP and NaF suggest this is also the case in $C$. burnetii. We have not been able to detect transport of methionine by $C$. burnetii. This amino acid in $E$. coli is reported to be transported directly from ATP hydrolysis rather than the $\Delta \bar{\mu}_{\mathrm{H}^{*}}$ (Kadner \& Winkler, 1975). Neither proline nor glutamate transport was affected by the citric acid cycle inhibitor sodium arsenite. In contrast, the enhanced transport of proline seen after incubation in glutamate (Fig. 3 ) was greatly decreased. The uptake of proline under these conditions, however, was still approximately $80 \%$ of the uptake of proline alone with inhibitor. The function of glutamate is probably to enhance the $\Delta \bar{\mu}_{\mathrm{H}^{*}}$ (Hackstadt, 1983). It is unlikely that proline and glutamate are transported on the same carrier, as glutamate at a 20 -fold greater concentration did not inhibit proline transport when added simultaneously with the labelled proline.

Proline transport has been shown to be highly specific for L-proline and several closely related analogues in other bacteria (Halpern, 1974). This also appears to be true in C. burnetii. However, some differences appear to exist between the specificity for certain analogues in $E$. coli and what we have observed in $C$. burnetii. Proline amide inhibited proline uptake in $E$. coli, but not in $C$. burnetii. Replacement of the nitrogen atom of proline, as in furoic acid, was not detrimental to recognition of the molecule in $C$. burnetii, while such compounds were inactive as inhibitors in $E$. coli (Rowland \& Tristram, 1975). These differences may be due partly to the different pH values at which transport occurs in the two organisms. The pI of proline is 6.3 (Segel, 1976). The effect of external pH on the protonization of ionizable groups in the substrate or substrate binding site must also be considered. 
The uptake and rapid metabolism of proline that we observed in C. burnetii contrasts sharply with the unusual transport of proline by Rickettsia prowazekii. With the latter organism, proline influx is linear for extended periods and metabolism of proline is not detected (Winkler \& Daugherty, 1984). While the transported proline serves as a substrate for metabolic processes in C. burnetii, it evidently serves a different, but unknown, function in $R$. prowazekii.

This work has been submitted to the Department of Bacteriology and Public Health. Washinglon State University, as a thesis by $\mathbf{L}$. H. in partial fulfilment of the requirements for the MS degree. This investigation was supported in part by funds provided to Washington State University through the NIH Biomedical Research Support Grant. We thank C. Elder and K. Nellermoe for expert preparation of the manuscript.

\section{REFERENCES}

Anderson, R. R., Menzel, R. \& WoOd, J. M. (1980). Biochemistry and regulation of a second L-proline transport system in Salmonella typhimurium. Journal of Bacteriology' 141, 1071-1076.

Baca, O. G. \& Paretsky. D. (1983). Q fever and Coxiella burnetii: a model for host-parasite interactions. Microbiological Revien's 47, 127-149.

Berger. E. A. (1973). Different mechanisms of energy coupling for the active transport of proline and glutamine in Escherichia coli. Proceedings of the National Academy of Sciences of the United States of America 70, 1514-1518.

Burton, P. R., Stueckman, J., Welsh, R. M. \& Paretsky, D. (1978). Some ultrastructural effects of persistent infection by the rickettsia Coxiella burnetii in mouse $L$ cells and green monkey kidney (VERO) cells. Infection and Immunity 21, 557-566.

DowD, J. E. \& RIGGs, D. S. (1965). A comparison of estimates of Michaelis-Menten kinetic constants from various linear transformations. Journal of Biological Chemistry 240, 863-869.

EtsenberG, A. D. \& MARquis, R. E. (1981). Enhanced transmembrane proton conductance in Sireptococcus mutans GS-5 due to ionophores and fluoride. Antimicrobial Agents and Chemotherapy 19, 807-812.

GIMENEZ, D. F. (1964). Staining rickettsiae in yolk-sac cultures. Stain Technology 39, 135-140.

Hackstadt, T. (1983). Estimation of the cytoplasmic $\mathrm{pH}$ of Coxiella burnerii and effect of substrate oxidation on the proton motive force. Journal of Bacteriology 154, 591-597.

Hackstadt, T. \& Williaks, J. C. (1981 a). Biochemical stratagem for obligate parasitism of eukaryotic cells by Coxiella burnetii. Proceedings of the National Academy of Sciences of the United States of America $78,3240-3244$.

HaCxstadt, T. \& WILliams, J. C. (1981 b). Stability of the adenosine $5^{\prime}$-triphosphate pool in Coxiella burnetii: influence of $\mathrm{pH}$ and substrate. Journal of Bacteriology 148, 419-425.

Hackstadt, T. \& Willums, J. C. (1983). pH dependence of the Coxiella burnetii glutamate transport system. Journal of Bacteriology 154, 598-603.

Halpern, Y. S. (1974). Genetics of amino acid Iransport in bacteria. Annual Review of Genetics 8 , 103-133.

Hendrix, L. R. \& Mallavia, L. P. (1983). Characteriz- ation of a proline active transport system in Coxiella burnetii. In Ahstracts of the Annual Meeting of the American Society for Microbiology D37. p. 65. Washington, DC: American Society for Microbiology.

KADNER, R. J. \& WINKLER, H. H. (1975). Energy coupling for methionine transport in Escherichia coli. Journal of Bacteriology 123, 985-991.

Kay, W. W. \& Gronlund, A. F. (1969). Proline transport by Pseudomonas aeruginosa. Biochimica et hiophy'sica acta 193, 444-454.

McCaul, T. F. \& Williams, J. C. (1981). Developmental cycle of Coxiella burnesii: structure and morphogenesis of vegetative and sporogenic differentiations. Journal of Bacteriology 147, 10631076.

OhKuMA, S. \& POOLE, B. (1978). Fluorescence probe measurement of the intralysosomal pH in living cells and the perturbation of $\mathrm{pH}$ by various agents. Proceedings of the National Academy of Sciences of the United States of America 75, 3327-3331.

Peterson, E. M. \& Calderone, R. A. (1978). Inhibition of specific amino acid uptake in Candida albicans by lysosomal extracts from rabbit alveolar macrophages. Infection and Immunity 21, 506-513.

RIB1, E. \& Hoyer. B. H. (1960). Purification of Q fever rickettsiae by density-gradient sedimentation. Journal of Immunology 85, 314-318.

Rowland, I. \& TRISTRam, H. (1975). Specificity of the Escherichia coli proline transport system. Journal of Bacteriology 123, 871-877.

Segel, I. H. (1976). Biochemical Calculations, 2nd edn. p. 411. New York: John Wiley \& Sons.

WEISS, E. (1982). The biology of rickettsiac. Annual Review of Microbiology 36, 345-370.

Williams, J. C., Peacock, M. G. \& McCaul, T. F. (1981). Immunological and biological characterization of Coxiella burnetii, phases I and II, separated from host components. Infection and Immunity 32, 840-851.

Winkler, H. H. \& Daugherty, R. M. (1984). Proline transport and metabolism in Rickettsia prowazekii. Journal of Bacteriology 158, 460-463.

WOOD, J. M. \& ZADWORNY, D. (1979). Characterization of an inducible porter required for L-proline catabolism by Escherichia coli K 12. Canadian Journal of Biochemistry 57, 1191-1199. 